\title{
Combining Multi-Criteria Decision Making (MCDM) Methods with Building Information Modelling (BIM): A Review
}

\author{
Tan $\operatorname{Tan}^{1 *}$, Grant Mills ${ }^{2}$, Eleni Papadonikolaki ${ }^{3}$, Zhening Liu $^{4}$
}

\begin{abstract}
Integrating building information to support decision-making has been a key challenge in the Architecture, Engineering, and Construction (AEC) industry. The synergy of Building Information Modelling (BIM) and Multi-Criteria Decision Making (MCDM) is expected to improve information integration and decision-making. The aim of this paper is to identify strategies to improve the synergy between MCDM and BIM. From the earliest literature (2009) to the present, this study examines 45 articles combining MCDM with BIM. We find that the five major application domains are sustainability, retrofit, supplier selection, safety, and constructability. Five established strategies for improving the synergy between MCDM and BIM were discussed and can be used as a benchmark for evaluating the application of decision techniques in practice. This study points out gaps of combining MCDM and BIM in the current literature. It also sheds new light into combining MCDM with BIM for practitioners, as to promote integrated decision-making.
\end{abstract}

Keywords: multi-criteria decision-making, BIM, building information modelling, review, decision analysis

\section{Introduction}

The success of construction projects depends heavily on decision-making [48]. Decisions are judgments based on information, and poor-quality information inevitably results in poor decision-making [35]. As building technology progresses, the complexity of projects and the information that requires integration has also increased. Process fragmentation and traditional practices have hindered the integration of knowledge and information among stakeholders, and

\footnotetext{
${ }^{1}$ Ph.D. Student, Corresponding Author, The Bartlett School of Construction \& Project Management, University College London, London, UK, WC1E 6BT, e-mail: tan.tan.17@ucl.ac.uk;

${ }^{2}$ Associate Professor, The Bartlett School of Construction \& Project Management, University College London, London, UK, WC1E 6BT, e-mail: g.mills@ucl.ac.uk

${ }^{3}$ Associate Professor, The Bartlett School of Construction \& Project Management, University College London, London, UK, WC1E6BT, e-mail: e.papadonikolaki@ucl.ac.uk

${ }^{4} \mathrm{Ph}$.D. Student, School of Management, University of Bath, Bath, UK, BA2 7BA, e-mail: zl2236@bath.ac.uk
} 
so undermines design decisions [71]. Building Information Modelling (BIM), as an innovative digital technology, is expected to transform the traditional process of information management [33]. Namely, horizontal integration among various stakeholders and vertical integration of information at different stages becomes possible with the incentive of BIM [17], which provides opportunities for integrating the fragmented Architecture, Engineering, and Construction (AEC) industry. Both geometric and non-geometric data are included in BIM models [90]. BIM integrates data from different disciplines and can quickly and accurately extract information from components and assist in evaluation [54,92]. However, the question remains how to integrate and utilize building information to facilitate decision-making.

Over the past decade, Multi-Criteria Decision Making (MCDM) has begun to demonstrate its capabilities to integrate technical information and multi-stakeholder value in BIM-based processes for decision-making. It compares and ranks decision-making schemes by integrating component - and often conflicting - indicators from all information sources into a single overall indicator [43]. Three main steps make up the MCDM: (1) define relevant alternatives and attributes; (2) link numerical measures to the relative importance of different attributes and to the impact of alternatives on these attributes and; (3) apply numerical measures to sort and rank different alternatives. There are numerous MCDM problems in the AEC industry [5,48,57]. The potential ability of MCDM in the AEC industry can be better stimulated through its synergy with BIM [23]. Vice versa, the implementation of BIM can also be promoted by MCDM which helps to overcome limitations of BIM related to optimizing multi-objectives while still exploiting its benefits [46].

MCDM is expected to play significant role during the transformation of AEC industry into digitization. However, there is no literature review of combining MCDM with BIM for decision-making to leverage the potential from their synergy, and no strategies are given for review the application of combining MCDM and BIM. Based on the observed knowledge gaps, the primary concerns of this study are:

- What application domains of the AEC industry use MCDM and BIM together?

- What MCDM techniques are used in conjunction with BIM?

- What strategies can be used for the improvement of the AEC industry by combining MCDM with BIM?

This review relies on 45 published papers in the field of AEC industry. In addition to methodology section, the paper is structured in four sections. The first part classifies the application domains using MCDM and BIM together. The second part categorizes MCDM techniques utilized with BIM. The third part is a discussion about five strategies for the improvement of combining MCDM with BIM. The last part is about conclusions and outlook 
for future research. The review is limited to publications from scientific journals, book chapters and international conferences, and only cover English articles. The purpose of this article is not to describe all the applications of BIM and MCDM in detail, but to identify the strategies to improve the synergy between MCDM and BIM from the literature.

\section{Methodology}

Systematic literature review uses an explicit and reproducible method to test hypothesis, summarize the results of existing studies, and evaluating consistency among previous studies. In addition, it aims to answer a specific question as well as reduce bias in the selection and inclusion of potential reviewed papers in objectively [77]. As systematic literature review is more transparent than other traditional and unsystematic review methods, it is relatively easy for other researchers to verify and replicate the study. Therefore, as this study aims at untangling and structuring pre-existing knowledge, it adopted a systematic literature review approach to answer the three questions stated in the introduction.

Large databases contain a large number of publications and convenient search mechanisms to implement complex logical expressions, and are therefore often used for systematic literature reviews. Two databases were used in this research, including Web of Science, Scopus Google Scholar, ProQuest, Springer Link, and ScienceDirect. As shown in Figure 1, the initial search included queries using a combination of MCDM-related keywords with "BIM". The selection of MCDM-related keywords was based on previous MCDM-related review studies used in [51,89], includes: "MCDM", "multi-criteria decision-making", "MCDA", "multi-criteria decision analysis", "Weighted sum methods", "Weighted product methods", "AHP", "Analytic hierarchy process", "TOPSIS", "VIKOR", "ANP", "Analytic network process", "DEA", "Data envelopment analysis", "Elimination and choice translating reality", "ELECTRE", "WASPAS", "Weighted aggregates sum product assessment". Articles published in journals, international conferences and book chapters were all considered. There was no restriction on the publication time in order to understand its overall development, but only English articles were considered.

Two rules were then complied for filtering out target literature: (a) identify whether BIM mentioned in results of the first screenings is "Building Information Modelling", which is to exclude literature from the non-AEC industry; (b) combine BIM and MCDM to tackle the construction issues, rather than solely use either BIM or MCDM to promote the other. Based on the second criterion, most of the excluded articles are related to use MCDM to identify factors about promotion or adoption of BIM. For example, Migilinskas, et al. [67] analysed problems, consequences and solutions for BIM application by using MCDM, and Chen and $\mathrm{Li}$ [21] proposed a AHP-based framework for BIM application assessment. Articles with a 
research scope like these two papers were removed under the exclusion criteria (b). Each article found was checked for its title, abstract and keywords to determine its relevance and importance. 45 papers were selected for further research. The earliest literature of combining MCDM with BIM was published in 2009, so the selected articles are from 2009-Aug 2020. Finally, the classifications were generated based on abstract, highlights and frequency of keyworks in articles. The authors then generated finding results in application domains (Section 3), MCDM methods (Section 4), and discussion (Section 5).

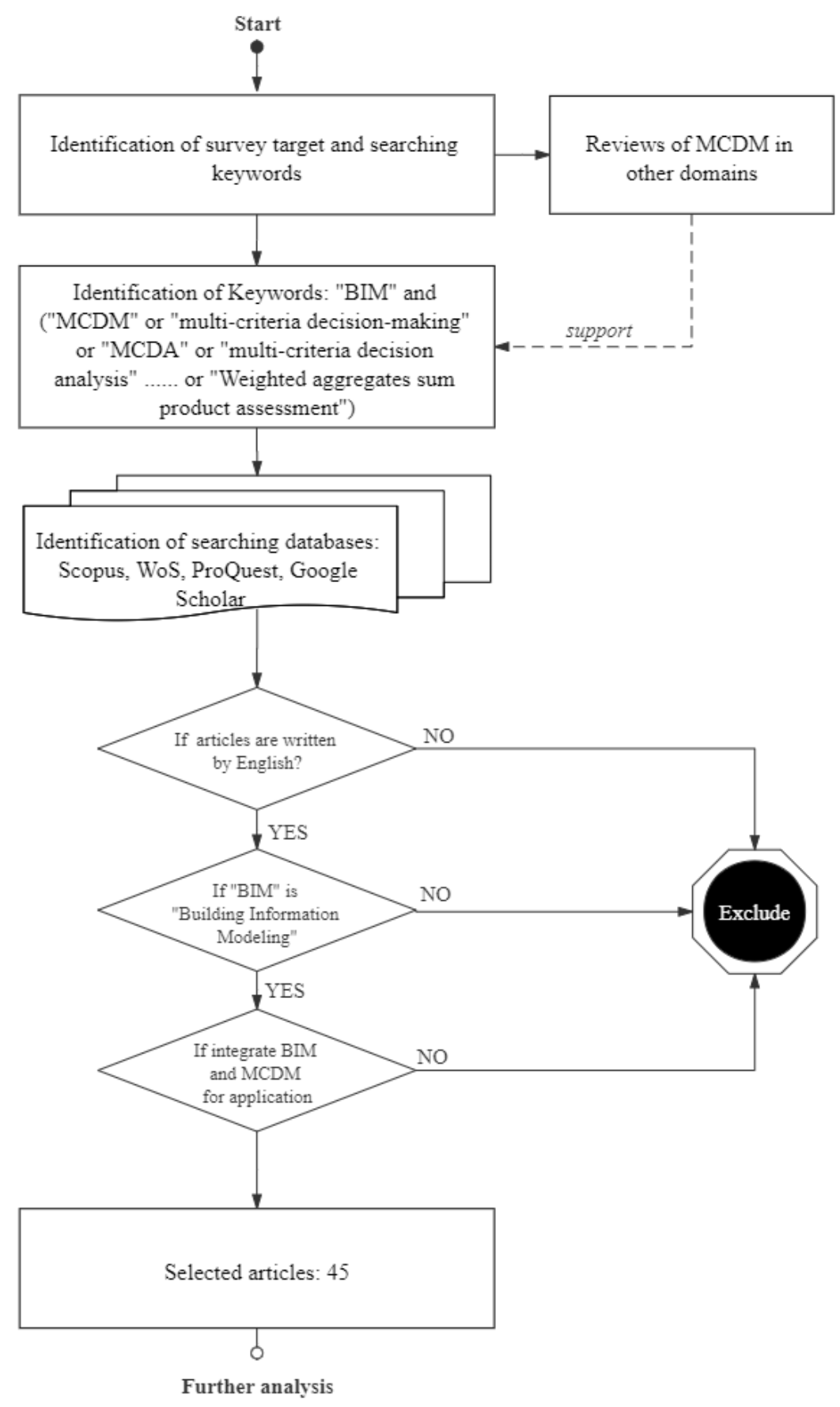

Figure 1 Paper selection process in the systematic literature review 
As for the data analysis, thematic analysis was firstly used to classify application domains. The authors classified the application domains inductively according to their abstracts, keywords and introductions. Six phases of data analysis include: (1) reading abstracts, keywords and introductions of screened papers; (2) generating codes by using Mendeley and Excel; (3) Generating initial sub-themes and themes; (4) reviewing themes; and (5) defining and naming themes. Finally, 16 subdomains were identified, and then further categorized into five major domains. If the domain investigated by articles only appears once, it would be classified into "Other".

Secondly, all papers' methodology parts were analysed by using the same thematic analysis method described above to classify MCDM techniques. Then, the author analysed the workflow to identify BIM functions and synergy approaches between MCDM and BIM. Totally, 41 out of 45 depict their framework in a workflow diagram. Thus, the author reviewed all workflow diagrams from 41 papers and methodology parts from 3 papers which does not have workflow diagrams. Finally, five corresponding strategies for the synergy between MCDM and BIM were generated and discussed to enhance three steps of MCDM, namely (1) define relevant alternatives and attributes; (2) link numerical measures to the relative importance of different attributes and to the impact of alternatives on these attributes and; (3) apply numerical measures to sort and rank different alternatives.

\section{Classification of application domains}

As shown in Table 1, five main application domains were identified, namely sustainability, retrofit, supplier selection chain, safety, and constructability. For each of the domains, several subdomains were further identified to narrow down this classification.

Table 1 Categorization of reviewed papers by domains.

\begin{tabular}{|l|l|l|l|}
\hline Domains & Subdomains & Reference & $\begin{array}{l}\text { Total } \\
\text { number }\end{array}$ \\
\hline \multirow{2}{*}{ Sustainability } & Sustainable building & {$[1,23,24,37,45,46,62,64,70,97,98]$} & 17 \\
\cline { 2 - 3 } & $\begin{array}{l}\text { Sustainable } \\
\text { component selection }\end{array}$ & {$[36,44,50,53,63,104]$} & \\
\hline Retrofit & Retrofit optioneering & {$[14,101]$} & 7 \\
\cline { 2 - 3 } & $\begin{array}{l}\text { Redevelopment } \\
\text { assessment }\end{array}$ & {$[74-76]$} & \\
\cline { 2 - 4 } & $\begin{array}{l}\text { Compliance checking } \\
\text { of retrofit }\end{array}$ & {$[11,12]$} & 4 \\
\hline \multirow{2}{*}{ Supplier } & Supplier selection & {$[4,61,99,107]$} & \\
\hline
\end{tabular}




\begin{tabular}{|c|c|c|c|}
\hline selection & & & \\
\hline \multirow[t]{5}{*}{ Safety } & Evacuation simulation & {$[13,65]$} & \multirow[t]{5}{*}{6} \\
\hline & $\begin{array}{l}\text { Building health } \\
\text { evaluation }\end{array}$ & [29] & \\
\hline & $\begin{array}{l}\text { Fall protection } \\
\text { planning }\end{array}$ & {$[66]$} & \\
\hline & $\begin{array}{l}\text { Safety prewarning } \\
\text { mechanism }\end{array}$ & [102] & \\
\hline & Fire risk assessment & [106] & \\
\hline \multirow[t]{4}{*}{ Constructability } & $\begin{array}{l}\text { Constructability } \\
\text { assessment }\end{array}$ & {$[31,41,42]$} & \multirow[t]{4}{*}{8} \\
\hline & Compliance checking & {$[2,3,56]$} & \\
\hline & $\begin{array}{l}\text { Design for } \\
\text { manufacture and } \\
\text { assembly }\end{array}$ & [39] & \\
\hline & Value engineering & [79] & \\
\hline \multirow[t]{3}{*}{ Other } & Cost & [10] & \multirow[t]{3}{*}{3} \\
\hline & Construction network & [40] & \\
\hline & Dispute & {$[18]$} & \\
\hline
\end{tabular}

\subsection{Sustainability}

Many reviewed papers (37.78\%) concerned sustainability assessment both for building level and component level. Sustainability is considered as a MCDM problem [28,47]. For the component level, Marzouk and Abdelakder [63] tried to identify the most sustainable materials by evaluating the construction project overall emissions and primary energy. Jalaei, et al. [44], Khanzadi, et al. [53] and Fazeli, et al. [36] proposed methods for optimal sustainable component selection. Yu and Woo [104] proposed a model for building-envelope structural modification system to increase energy efficiency. Façade also has been enhanced by MCDM for "green" ability by Juszczyk and Zima [50]. For the building level, Wang [97] used BIM and MCDM for environment assessment of full life cycle. Chen and Pan [23] developed a model for low carbon building measures selection. Naji, et al. [70] tried to control building temperature and reduce the electricity demand. Mahmoud, et al. [62] developed a global sustainability rating tool for existing buildings. Jalilzadehazhari, et al. [46] applied MCDM and BIM to take account energy requirements of buildings while simultaneously improving indoor environment quality. 
It can be observed that the integration of BIM and MCDM has been profusely applied in sustainability-related issues in the AEC industry.

\subsection{Retrofit}

Integrating BIM and MCDM can strongly support the objective comparison of different solutions to help consider all aspects in the retrofit decision Cecconi, et al. [14]. In our review, retrofit also occupies a certain share (15.56\%). Pavlovskis, et al. [76] developed a method to rank heritage building conversion alternatives. Carbonari, et al. [12] and Carbonari, et al. [11] proposed a method to evaluate the compliance of existing buildings with the latest standards. Cecconi, et al. [14] delivered a system of procedures and instruments that allows comparing different scenarios of restoration and retrofit of existing buildings applicable each time a relevant decision about the asset has to be made. Pavlovskis, et al. [74] and Pavlovskis, et al. [75] developed a method for abandoned former industrial buildings problems and buildings' redevelopment possibilities. Woo and Menassa [101] proposed a framework that supports streamlined decision making for building retrofit projects. Hence, retrofit optioneering, redevelopment assessment, compliance checking of retrofit all have potential to utilize BIM and MCDM.

\subsection{Supplier selection}

Supplier selection is indeed a MCDM process which comprises diverse opinions, and is confronted by various alternatives for the final outcome [81]. In our review, four papers (8.89\%) concerned about supplier selection. Mahamadu, et al. [61] proposed a computational framework capable of enhancing decision making during the selection process through a robust approach to the aggregation and comparison of SC firm's BIM competence and readiness. Wang, et al. [99] integrating BIM and GIS to generate supplier selection framework for a resilient construction supply chain. Zhao, et al. [107] presented a BIM-based method by using to rank the importance of the assessment criteria and obtain the score of supplier alternatives for supporting supplier selection of a prefabrication project. Alireza, et al. [4] proposes a novel framework for sustainability assessment of construction material supply chain decisions by taking advantage of the information made available by customized BIM and a number of different databases required for assessment of life cycle impacts. MCDM is a method derived from operations research, and supply chain management is a frequently discussed topic in operations research. It is foreseeable that many related MCDM research in the supply chain may be applied to construction supply chain. It is also worth to notice that many of these 
methods rely on the information richness and transparent level of BIM. However, inevitable external risks and variations in construction supply chain increase the challenges to the methods' reliability.

\subsection{Safety}

Some researchers integrated BIM and MCDM to solve safety-related problems in the AEC industry. In our reviewed papers, there are six studies (13.33\%) related to safety. It also can be observed that these studies are all currently concentrated on the construction and operation stages. For construction stage, Ding, et al. [29] proposed an approach to evaluate the building health related to the safety and health of users. Castillo Osorio and Yoo [13] developed a method for calculation of the most feasible evacuation route inside buildings. For operation stage, Marzouk and Daour [65] established framework estimates the execution time, total cost, and evacuation time for construction projects, taking safety into consideration. Melzner, et al. [66] developed a structured and uniform system for choosing the most favourable fall protection system to prevent falling from slabs.

\subsection{Constructability}

Eight articles (17.78\%) focus on how to make the building design more constructable during the design stage. Several studies try to integrate MCDM and BIM for automatic compliance checking for design schemes, as manually reviewing whether the design meets the rules and regulations that allow it to be built is very time-consuming and can easily lead to many errors and omissions [56]. Lee, et al. [56] proposed a method to provide recommending alternatives to designers after automatic rules checking. Al-Bukhari and Hegazy [2] and Albukhari and Hegazy [3] developed method for submittal review that evaluates all the material, equipment, and processes submitted by a contractor, for compliance with specifications, before being installed in a project. In addition, constructability assessment, Design for Manufacture and Assembly (DfMA), and value engineering are also mentioned in these reviewed papers. Hijazi, et al. [42] and Hijazi, et al. [41] established a method for constructability assessment. Gbadamosi, et al. [39] proposed a method to integrates the principles of DFMA and Lean Construction to develop a design assessment and optimization system to assist designers in the selection of alternative building design elements and materials in a building information model. Ranjbaran and Moselhi [79] developed an automated model for design professionals, owners and members of value engineering teams to evaluate and compare different design alternatives 
of project components using multi-attributed criteria as well as integrating that model with visualization capabilities to assist designers and stakeholders in making related decisions.

\subsection{Other application domains}

In addition to the above, some application domains with little attention are also reported (6.67\%). Cao and Zheng [10] established a method for the cost decision of construction project and promote the application of BIM in cost management. Grilo, et al. [40] developed a model that captures the factors for the deployment of building BIM that are responsible for business interoperability in the context of collaborative business processes' construction networks. Charehzehi, et al. [18] proposed an approach to control conflict causes before the occurrence of dispute. These directions show the broad application prospect of the synergy between MCDM and BIM, but more research and practices are still required to fill emerging theoretical and practical gaps.

\section{Classification of MCDM methods}

To tackle arduous decision-making problems in abovementioned application domains, various MCDM techniques have been developed by researchers. Table 2 is the description of MCDM techniques classified in this section. As shown in Table 3, the reviewed papers were categorised into individual and hybrid MCDM approaches based on whether the paper uses a single technique or a hybrid of multiple techniques. The following contents of this section reveal the essential definition and the primary application of identified MCDM techniques.

Table 2 Description of MCDM techniques

\begin{tabular}{|l|l|l|l|}
\hline $\begin{array}{l}\text { MCDM } \\
\text { techniques }\end{array}$ & Acronyms & Description & Reference \\
\hline $\begin{array}{l}\text { Analytic Hierarchy } \\
\text { Process }\end{array}$ & AHP & $\begin{array}{l}\text { A structured technique for } \\
\text { organizing and } \\
\text { analyzing complex decisions }\end{array}$ & Saaty [87] \\
\hline $\begin{array}{l}\text { Analytic Network } \\
\text { Process }\end{array}$ & ANP & $\begin{array}{l}\text { Generalization of the } \\
\text { AHP method which enables } \\
\text { the existence of } \\
\text { interdependencies among } \\
\text { criteria }\end{array}$ & Saaty [84] \\
\hline $\begin{array}{l}\text { Technique for order } \\
\text { of preference by } \\
\text { similarity to ideal } \\
\text { solution }\end{array}$ & TOPSIS & $\begin{array}{l}\text { A method of compensatory } \\
\text { aggregation }\end{array}$ & $\begin{array}{l}\text { Yoon and Hwang } \\
{[103]}\end{array}$ \\
\hline $\begin{array}{l}\text { Multi-attribute } \\
\text { utility theory }\end{array}$ & MAUT & $\begin{array}{l}\text { Methodology employed to } \\
\text { make decisions by comparing } \\
\text { the utility values of a series of }\end{array}$ & Edwards [34] \\
\hline
\end{tabular}




\begin{tabular}{|c|c|c|c|}
\hline & & $\begin{array}{l}\text { attributes in terms of risk and } \\
\text { uncertainty }\end{array}$ & \\
\hline $\begin{array}{l}\text { Preference ranking } \\
\text { organization } \\
\text { method for } \\
\text { enrichment of } \\
\text { evaluations }\end{array}$ & PROMETHEE & $\begin{array}{l}\text { Family of outranking methods } \\
\text { based on the selection of a } \\
\text { preference function for each } \\
\text { criterion forming a MCDM } \\
\text { problem }\end{array}$ & $\begin{array}{l}\text { Brans and Vincke } \\
\text { [9] }\end{array}$ \\
\hline $\begin{array}{l}\text { Weighted } \\
\text { Aggregates Sum } \\
\text { Product } \\
\text { Assessment }\end{array}$ & WASPAS & $\begin{array}{l}\text { A combination of weighted } \\
\text { sum model (WSM) and } \\
\text { weighted product model } \\
\text { (WPM). }\end{array}$ & $\begin{array}{l}\text { Zavadskas, et al. } \\
{[105]}\end{array}$ \\
\hline $\begin{array}{l}\text { VlseKriterijumska } \\
\text { Optimizacija I } \\
\text { Kompromisno } \\
\text { Resenje }\end{array}$ & VIKOR & $\begin{array}{l}\text { A compromise approach of } \\
\text { MCDM, determines the best } \\
\text { alternative by ranking the } \\
\text { closeness to the ideal } \\
\text { solution. }\end{array}$ & Opricovic [72] \\
\hline $\begin{array}{l}\text { Elimination and } \\
\text { Choice Translating } \\
\text { Reality }\end{array}$ & ELECTRE & $\begin{array}{l}\text { An outranking method of } \\
\text { MCDM, sorts out the best } \\
\text { alternative by comparing each } \\
\text { pair of actions based on } \\
\text { several outranking relations. }\end{array}$ & $\begin{array}{l}\text { Benayoun, et al. } \\
{[8]}\end{array}$ \\
\hline $\begin{array}{l}\text { Data Envelopment } \\
\text { Analysis }\end{array}$ & DEA & $\begin{array}{l}\text { A non-parametric linear } \\
\text { programming method to } \\
\text { measure the production } \\
\text { frontiers by comparison with } \\
\text { the best producer in the } \\
\text { sample to derive compared } \\
\text { efficiency. }\end{array}$ & Charnes, et al. [19] \\
\hline
\end{tabular}

Table 3 Proportion of MCDM techniques

\begin{tabular}{|c|c|c|c|c|c|}
\hline $\begin{array}{c}\text { MCDM } \\
\text { approac } \\
\mathbf{h}\end{array}$ & $\begin{array}{c}\text { MCDM } \\
\text { technique } \\
\text { s }\end{array}$ & $\begin{array}{c}\text { NO. of } \\
\text { occurren } \\
\text { ces }\end{array}$ & $\begin{array}{c}\text { \% of } \\
\text { single/hy } \\
\text { brid }\end{array}$ & $\begin{array}{c}\text { \% of } \\
\text { total }\end{array}$ & Reference \\
\hline Single & AHP & 20 & 95.24 & 44.4 & $\begin{array}{c}{[1,10,13,29,31,37,39,41,42,45,46} \\
, 50,66,70,79,97,101,104,106,107 \\
]\end{array}$ \\
\cline { 2 - 6 } & ANP & 1 & 4.76 & 2.22 & {$[40]$} \\
\hline Hybrid & $\begin{array}{c}\text { AHP+TOP } \\
\text { SIS }\end{array}$ & 3 & 12.50 & 6.67 & {$[4,56,65]$} \\
\cline { 2 - 6 } & $\begin{array}{c}\text { AHP+MA } \\
\text { UT }\end{array}$ & 3 & 12.50 & 6.67 & {$[2,3,18]$} \\
\cline { 2 - 6 } & $\begin{array}{c}\text { Fuzzy+TO } \\
\text { PSIS }\end{array}$ & 3 & 12.50 & 6.67 & {$[36,61,98]$} \\
\cline { 2 - 6 } & $\begin{array}{c}\text { Fuzzy+PR } \\
\text { OMETHE } \\
\text { E }\end{array}$ & 2 & 8.33 & 4.44 & {$[23,24]$} \\
\cline { 2 - 6 } & Other & 13 & 54.17 & 28.8 & {$[11,12,14,44,53,62-64,74-$} \\
& & & & $76,99,102]$ \\
\hline
\end{tabular}

The authors classified the MCDM techniques by application domains (Figure 2), and application domains by MCDM methods (Figure 3). It can be observed that AHP-based models and TOPSIS-based models are widely applied in different application domains. All application 
domains adopted AHP as part of their approach. And TOPSIS is used in most application domains. As shown in Table 4, MCDM techniques further classified the MCDM techniques by method classification, data type and criteria structure. It can be observed pairwise comparisonbased methods are the most widely applied.

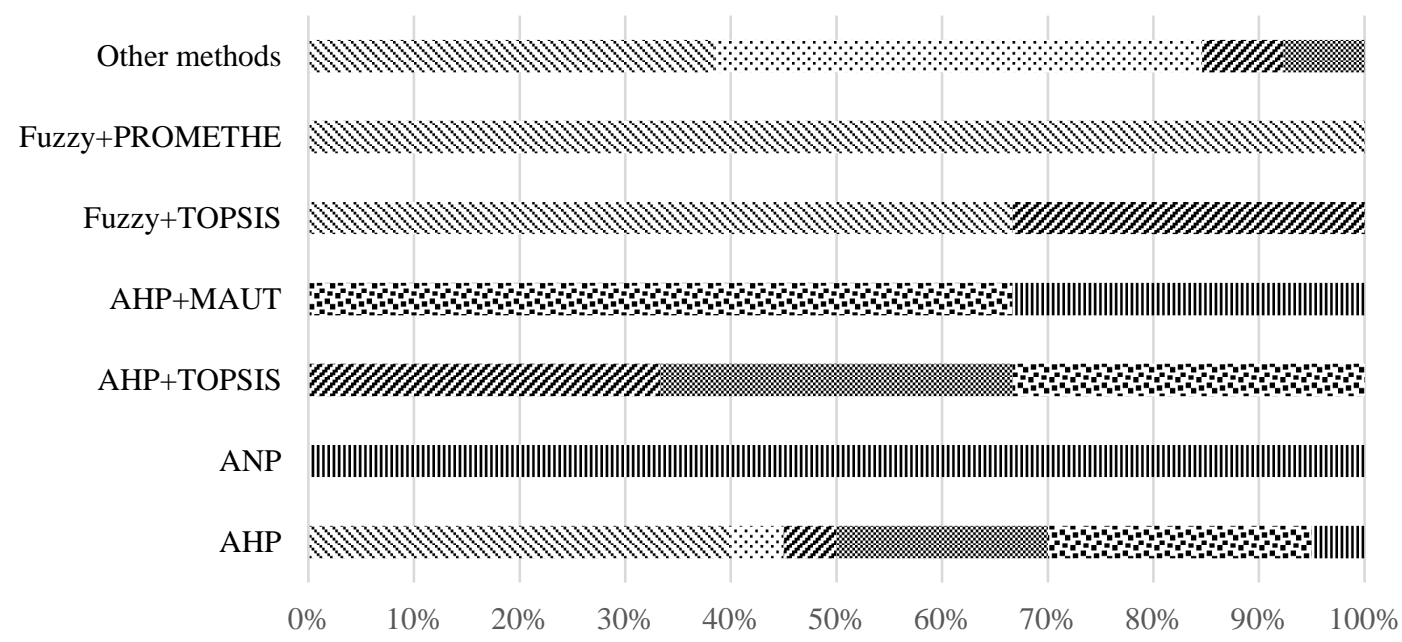

$\approx$ Sustainability $\approx$ Retrofit $\approx$ Supplier selection $\approx$ Safety $\approx$ Constructability IIII Other

Figure 2 Categorization of MCDM techniques by application domains

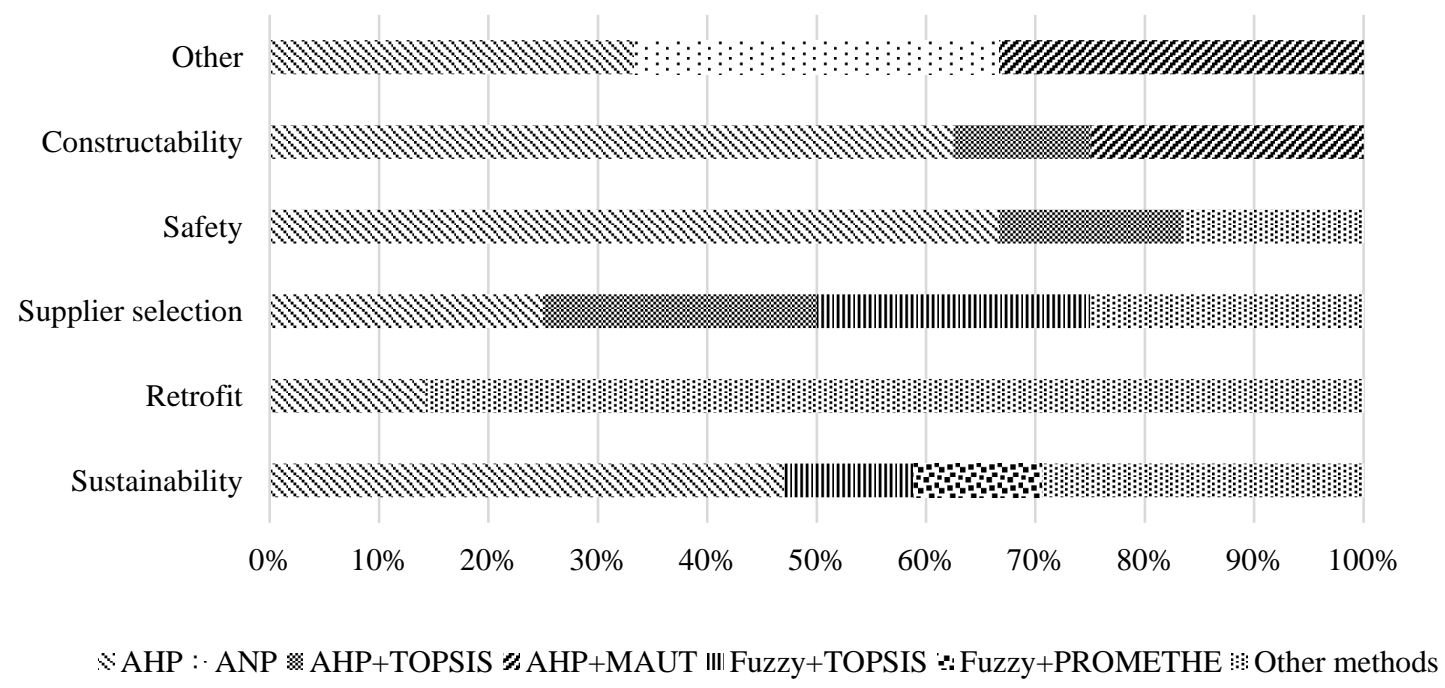

Figure 3 Categorization of application domains by MCDM techniques

Table 4 Classification of MCDM techniques 


\begin{tabular}{|c|c|c|c|c|c|c|}
\hline \multirow{2}{*}{$\begin{array}{c}\text { M } \\
\text { CD } \\
\text { M } \\
\text { ap } \\
\text { pro } \\
\text { ach }\end{array}$} & \multirow{2}{*}{$\begin{array}{c}\text { MCDM } \\
\text { techniqu } \\
\text { es }\end{array}$} & \multirow[t]{2}{*}{ Method classification } & \multicolumn{2}{|c|}{$\begin{array}{l}\text { Data } \\
\text { type }\end{array}$} & \multirow{2}{*}{$\begin{array}{l}\text { Criteri } \\
\text { a } \\
\text { struct } \\
\text { ure }\end{array}$} & \multirow[t]{2}{*}{ Reference } \\
\hline & & & $\begin{array}{l}\mathrm{C} \\
\text { ri } \\
\mathrm{s} \\
\mathrm{p}\end{array}$ & $\begin{array}{l}\mathrm{F} \\
\mathrm{uz} \\
\mathrm{zy}\end{array}$ & & \\
\hline \multirow[t]{2}{*}{$\begin{array}{l}\text { Sin } \\
\text { gle }\end{array}$} & AHP & $\begin{array}{l}\text { Pairwise comparison- } \\
\text { based methods }\end{array}$ & $\checkmark$ & & $\begin{array}{c}\text { Hierarc } \\
\text { hy }\end{array}$ & $\begin{array}{c}{[1,10,13,29,31,37,39,41,4} \\
2,45,46,50,66,70,79,97,10 \\
1,104,106,107] \\
\end{array}$ \\
\hline & ANP & $\begin{array}{c}\text { Pairwise comparison- } \\
\text { based methods }\end{array}$ & $\checkmark$ & & $\begin{array}{c}\text { networ } \\
\mathrm{k}\end{array}$ & [40] \\
\hline \multirow[t]{10}{*}{$\begin{array}{c}\text { Hy } \\
\text { bri } \\
\text { d }\end{array}$} & $\begin{array}{l}\text { AHP+TO } \\
\text { PSIS }\end{array}$ & $\begin{array}{l}\text { Pairwise comparison- } \\
\text { based methods+ } \\
\text { Distance-based methods }\end{array}$ & $\checkmark$ & & $\begin{array}{c}\text { Hierarc } \\
\text { hy }\end{array}$ & {$[4,56,65]$} \\
\hline & $\begin{array}{c}\text { AHP+M } \\
\text { AUT }\end{array}$ & $\begin{array}{l}\text { Pairwise comparison- } \\
\text { based methods+ } \\
\text { Optimizing average }\end{array}$ & $\checkmark$ & & $\begin{array}{l}\text { Hierarc } \\
\text { hy }\end{array}$ & {$[2,3,18]$} \\
\hline & $\begin{array}{c}\text { Fuzzy+T } \\
\text { OPSIS }\end{array}$ & Distance-based methods & & $\checkmark$ & $\begin{array}{l}\text { Indepe } \\
\text { ndence }\end{array}$ & {$[36,61,98]$} \\
\hline & $\begin{array}{c}\text { Fuzzy+P } \\
\text { ROMET } \\
\text { HEE }\end{array}$ & Outranking methods & & $\checkmark$ & $\begin{array}{l}\text { Indepe } \\
\text { ndence }\end{array}$ & {$[23,24]$} \\
\hline & $\begin{array}{l}\text { AHP+De } \\
\text { lphi }\end{array}$ & $\begin{array}{l}\text { Pairwise comparison- } \\
\text { based methods }\end{array}$ & $\checkmark$ & & $\begin{array}{c}\text { Hierarc } \\
\text { hy }\end{array}$ & [14] \\
\hline & $\begin{array}{c}\mathrm{AHP}+\mathrm{GR} \\
\mathrm{A}\end{array}$ & $\begin{array}{l}\text { Pairwise comparison- } \\
\text { based methods+ } \\
\text { Distance-based methods }\end{array}$ & & $\checkmark$ & $\begin{array}{c}\text { Hierarc } \\
\text { hy }\end{array}$ & {$[99,102]$} \\
\hline & $\begin{array}{c}\mathrm{AHP}+\mathrm{Ba} \\
\text { yesian } \\
\text { networks }\end{array}$ & $\begin{array}{l}\text { Pairwise comparison- } \\
\text { based methods }\end{array}$ & $\checkmark$ & & $\begin{array}{l}\text { Hierarc } \\
\text { hy }\end{array}$ & {$[11,12]$} \\
\hline & $\begin{array}{l}\text { WASPA } \\
\text { S-Rough }\end{array}$ & Optimizing average & & $\checkmark$ & $\begin{array}{l}\text { Indepe } \\
\text { ndence }\end{array}$ & [76] \\
\hline & $\begin{array}{l}\text { WASPA } \\
\text { S-Grey }\end{array}$ & Optimizing average & & $\checkmark$ & $\begin{array}{l}\text { Indepe } \\
\text { ndence }\end{array}$ & {$[74,75]$} \\
\hline & $\begin{array}{l}\text { Entropy+ } \\
\text { TOPSIS }\end{array}$ & Distance-based methods & $\checkmark$ & & $\begin{array}{l}\text { Indepe } \\
\text { ndence }\end{array}$ & [44] \\
\hline
\end{tabular}

\subsection{Individual MCDM approach}

\subsubsection{The Analytic Hierarchy Process (AHP)}

The AHP has a pivotal role in the metabolism of MCDM, and it was first established by Thomas L. Saaty in 1970s. By definition, the AHP is a decision-making tool that leveraging pairwise comparisons to derive the priority scales of complex criteria and constrains based on linear algebra $[32,85,87]$. Twenty $(44.44 \%)$ articles we identified proposed AHP as an individual MCDM approach as a part of their solutions. Despite has multifaceted advantages such as simplicity and flexibility, the AHP can only take into account a limited number of criteria and alternatives. Whilst the AHP has relative strict requirement for the independence between 
criteria and the results of using the AHP are strongly contingent on pairwise comparisons [46], which pointed out the potential bias of this approach.

\subsubsection{The Analytic Network Process (ANP)}

The ANP, another individual MCDM approach, is the generalization of the AHP [86]. Both methods focus on decomposing complex multidimensional problems and finding trade-off solutions between different decision criteria by pairwise comparisons. Nevertheless, the ANP tackle the interdependence and feedback problem of elements and break the constraint of hierarchical structure in the AHP [88]. Instead, ANP structure the decision problem into a network. One article in reviewed paper proposed the ANP to improve the performance of business interoperability for BIM-based projects. Grilo, et al. [40] developed a BIQMM model to quantitatively analyse the business interoperability based on the ANP. The ANP was selected to manipulate the supermatrix developed by pairwise comparisons of 8 business interoperability parameters and comprehensively score the performance of different alternatives.

\subsection{Hybrid MCDM approach}

\subsubsection{AHP+TOPSIS}

The Technique for Order Preference by Similarity to an Ideal Solution (TOPSIS) was proposed to prioritize the solutions and identify the best alternative based on its geometric distance from ideal solutions [103]. To be specific, the positive ideal solution (PIS) maximize the salutary elements and minimize the infaust elements. Inversely, the negative ideal solution (NIS) maximize the infaust elements and minimize the salutary elements, and the best alternative is the one nearest to the PIS while furthest from NIS [6]. Some research couple the AHP and the TOPSIS to rank the potential alternatives, as the AHP can systematically weight the decision criteria while the TOPSIS can list and detect alternatives according to the reality situation [73]. It has been observed that 3 papers integrate the AHP and TOPSIS in our review scale. No doubt that the combination of AHP-TOPSIS can assist decision maker to build a robust evaluation foundation. However, the existing of fuzzy information can make unignorable impact on the accuracy, which provide room for future improvement [56].

\subsubsection{AHP+MAUT}

The MAUT, also known as Multi Attribute Utility Theory, is a tool to represent the preference of decision maker by comparing the utility values of numerous attributes and criteria under conditions of uncertainty $[34,96]$. The utilization of MAUT can compensate the performance 
of each criterion and make the decision-making process more precise and transparent [27]. To integrate AHP and MAUT can alleviate the personal error of the algorithm [18].

\subsubsection{Fuzzy+TOPSIS}

MCDM in fuzzy environment was first introduced by Bellman and Zadeh [7]. The fuzzy set theory allows ambiguous qualitative or quantitative information converting into computable equivalents and helps decision makers to solve real life problems more accurate [69]. The combination of fuzzy and TOPSIS eliminate the defect of traditional TOPSIS that has difficult in making judgments only depending on crisp values [36].

\subsubsection{Fuzzy+PROMETHEE}

Rather than assuming the existence of an absolute best option, the Preference Ranking Organization METHod for Enrichment of Evaluations (PROMETHEE) regards that one alternative has dominance over another in some degree, and can contribute to the most suitable choice [9,52]. The PROMETHEE adopts preference functions to rank alternatives depending on their net flows, which allows the absence of complex criteria metrics [58]. The preponderance of fuzzy set theory in MCDM issues ensures the incorporation of the fuzzy and PROMETHEE. The coordinate of fuzzy-PROMETHEE can get the utmost out of the available information and make the impartial decision without plenty subjective data $[16,25]$.

\subsubsection{Others}

There are also some other hybrid MCDM methods. For instance, the Delphi method is an interactive tool to solve MCDM problems through a structured group of experts [26]. Combining AHP and Delphi can obtain a consistent and reliable opinion from questionnaires adjusted with pairwise comparison and filled by experts [14]. Besides, the integration of AHP and Grey Relational Analysis (GRA) is also able to considerate the uncertainty, fuzziness and interrelationships during the process of weighting criteria and ranking alternatives [99]. Likewise, Weighted Aggregated Sum Product Assessment (WASPAS) method [105] often associate with grey attributes scores to make logical choice among alternatives in vague environment depending on the criteria matrix [75].

Few studies have tried to integrate multi-objective optimisation (e.g. linear programming, genetic algorithm) into MCDM to create a hybrid tool. Pareto front generated from multiobjective optimisation can be then processed by MCDM to sort the set according to user's subjective preference information. For example, Marzouk and Abdelakder [63] proposed a hybrid fuzzy-optimization by applying non-dominated sorting genetic algorithm II (NSGA-II), then selected the most sustainable building material from a set of Pareto optimal solutions by TOPSIS. This hybrid integration avoids transforming MCDM into a single objective by using 
a priori set of weights. And posteriori gained from knowledge on the target problems from the specific optimization results can help achieve a true Pareto front more wisely. Future research can try to integrate and expand these methods' application with BIM to solve AEC problems.

\section{Discussion}

As shown in Figure 4, there is a significant upward trend in the last decade in combining MCDM with BIM. To deepen and extend our understanding of the synergy between BIM and MCDM, our research systematically reviewed the academic literature and drawing upon 45 papers, has suggested mainly five application domains, six MCDM techniques and three BIM functions. The five application domains summarizing our research findings are: sustainability, retrofit, supplier selection, safety, and constructability. The six most frequently occurring MCDM techniques includes AHP, ANP, AHP+TOPSIS, AHP+MAUT, Fuzzy+TOPSIS, and Fuzzy+RPOMETHEE. Three BIM functions are model database, processing tool, and information intermediary. The classifications were identified to illustrate the synergy approaches of the synergy between BIM and MCDM, as well as to contribute to the ongoing conversations in the literature. In this section, we carefully discuss what strategies can be learnt from the literature for the improvement of combining MCDM with BIM. Five strategies for successfully combining MCDM with BIM are: (1) setting reasonable multi-criteria for target problem; (2) fully exert BIM functions in MCDM process; (3) collaborating BIM and MCDM for the target problem; (4) identifying MCDM techniques and data collection methods based on the characteristics of building stages; (5) optimize the information richness of BIM to adapt to MCDM techniques.

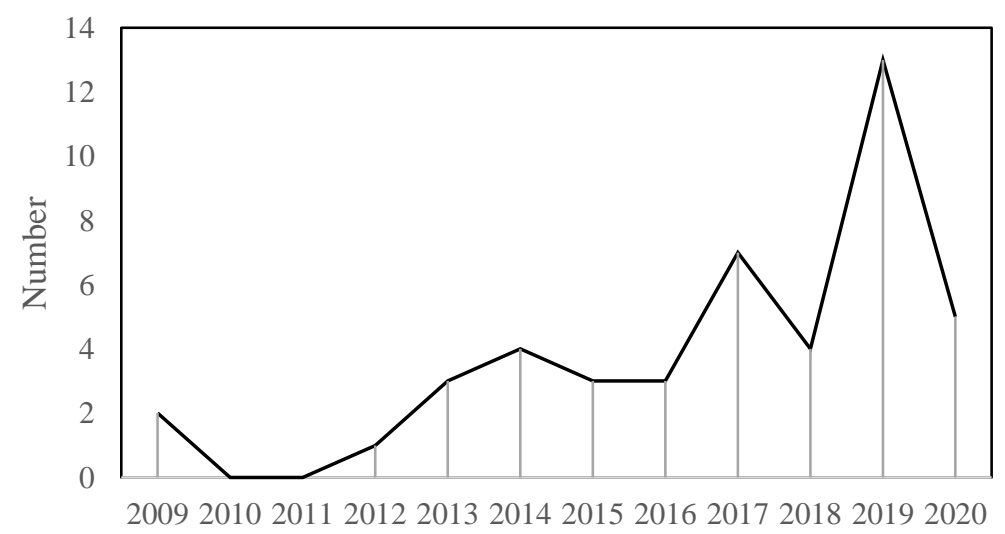

Figure 4 Categorization of reviewed papers by publication year (2009-Aug 2020) 


\subsection{Setting reasonable multi-criteria for target problem}

It can be observed that the synergy between MCDM and BIM has prospect in many AEC domains. Many new fields and concepts emerging in the reviewed papers may have different interpretations and definitions of these concepts in their practices or studies, such as sustainability [68], constructability [78], DfMA [38] and safety management [49]. In our reviewed papers, there are similar consensus and actions that these abstract concepts are defined by a set of indicators to deal with practical problems. Namely, these abstract and intangible concepts are specified through adequately defining a pluridisciplinary list of acceptable criteria and indicators, which is actually a pragmatism attitude to facilitate decision-making process. This also implies that concepts established by a set of indicators can use MCDM methods for decision-making. A tacit assumption is that the abstract concepts generated by human beings can be broken down, measured and tested. The research combining MCDM and BIM reports the presentation of MCDM models' logic and comparison of simulation results.

Future research can go beyond the scope of above five major application domains, and explore more potential domains and scenarios in the AEC industry. For example, emerging topics, such as blockchain, Internet of Things (IoT) and digital twin, all have a potential to provide a more enriched environment for the integration of MCDM and BIM. Future research can explore how to better obtain, store and process data through these emerging technologies to assist MCDM. In addition, new industrialized techniques, such as robotic arms and 3D printing, provide new scenarios for architectural design (e.g. design for additive manufacturing, product family design, generative design), off-site manufacturing (e.g. additive manufacturing, modularization, space technology in construction), on-site assembly (e.g. automated approaches in construction, human robot collaboration, powered exoskeleton), and cognitive facility management (e.g. sensor network, infrastructure inspection). These emerging technologies innovate the traditional construction process, which will provide new scenarios for MCDM. When defining a target problem in application domains, determining a set of reasonable multi-criteria is the first step in developing the corresponding MCDM techniques [94]. The establishment of multicriteria directly affects the quality of decision-making, which requires relevant researchers to carefully screen multi-criteria and repeatedly verify reliability from literature and empirical data.

\subsection{BIM functions in MCDM process}

Drawing upon the results, there are three major functions of BIM: 1) Model database, storing both geometric information and non-geometric information; 2) Processing tool, assisting collect, categorize, modify, and analysis data; 3) Information intermediary, assisting formats 
conversion and information exchange. Although, this was not a pre-defined objective of the study, three functions of BIM were emerging findings in the study.

Firstly, a significant function of BIM mentioned in reviewed papers is to store information as a database [12,13,29,63,107]. A BIM-enabled MCDM process might include various data type, including stakeholders requirement data, standards and regulations data, expert knowledge data, users related data [37], and building related data, such as existing documentation, photogrammetry, and data from sensors. Some studies regard BIM as a central repository of information for decision-making [14], or as a key data supplement source to other central repository, such as MS Access [99].

Secondly, BIM's role as an information processing tool has also been proposed by many reviewed papers, including collect [29], categorize [107], modify [1,29], update [3,29], and analysis information [3]. And BIM environment provides a hotbed for plug-in development, which further facilitate the above sub-functions $[12,53,65]$. For example, links can be built between BIM' tool and MCDM analysis tool by designing plugs-in [44], which also facilitate extraction of information [10], and integration of decision-making parameters [36].

Thirdly, BIM can act as an information intermediary to assist formats conversion and information exchange. For example, Ahmad and Thaheem [1] expanded BIM capabilities by using Application Programming Interface (API) to integrate BIM with a MCDM model for smoother information exchange. The potential capabilities of this integration are also highlighted by Marzouk and Daour [65] for adding customized toolbars, functionality, and connectivity to external application. In general, expanding BIM functions into MCDM and fully exerting BIM functions in MCDM process are expected to enhance the combination and interaction of these two approaches.

\subsection{Synergy approaches between MCDM and BIM}

Many studies proposed their own framework of combining BIM and MCDM for their identified questions. 41 out of 45 depict their framework in a workflow diagram. Generally, there are two synergistic structures, namely linear structure and integrated structure. The former one is widely used, and more than half of our reviewed papers used this way. As shown in Figure 5, linear structure is a one-way workflow from BIM to MCDM. The input for BIM includes various building or project-related data. The input for MCDM includes proposed multi-criteria and attribute of multi-criteria. The former one usually identified through literature review. The latter is generated through interview, survey, brainstorm, or expert opinions. Then, the BIM data will be introduced into MCDM and generate evaluation results. 


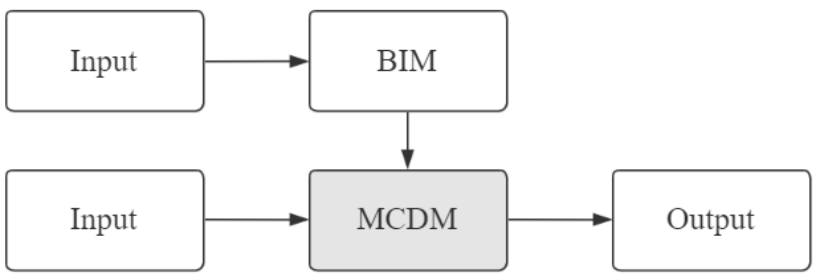

Figure 5 Linear structure

As shown in Figure 6, integrated structure has a two-way interaction. BIM firstly acts as a data foundation for MCDM processing, and then MCDM generates results which are exported back to the BIM platform [2,3], to present results [36], and store performance evaluation results for further use [14]. Compared with the linear structure, the synergy approach of the integrated structure is more conducive to fully realize the interaction between BIM and MCDM. However, in the currently screened literature, less than five articles apply the integrated structure and mainly utilize BIM as a database function at the end of the MCDM process to store the results. This level of integration may not really show its difference from linear structure. Therefore, it cannot be concluded in turn that the decision result of integrated structure must be superior to the linear structure.

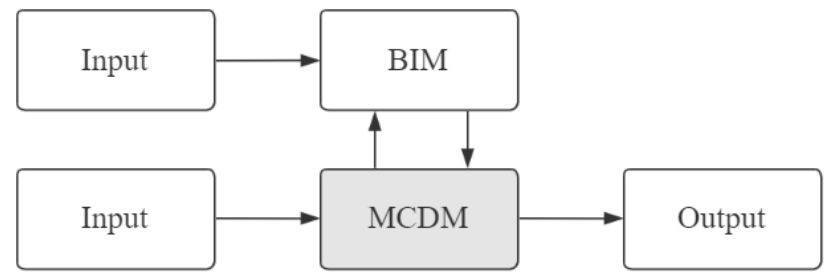

Figure 6 Integrated structure

\subsection{Corresponding MCDM techniques and BIM for different building stages}

In addition to the synergy approaches, the building stage also affects the synergy between BIM and MCDM due to the unevenness of BIM's semantic enrichment at different building stages. As shown in Figure 7, the synergy between BIM and MCDM application in operation phase is currently the least in number when compared with planning, design, and so on. Volk, et al. [95] and Carbonari, et al. [12] shared a possible reason is that there is a large amount of modelling effort required to convert information from Computer-Aided Design (CAD) or paper documents to BIM models, which usually forces managers to deal with a lot of uncertain or missing information. Wang, et al. [99] also pointed that some information cannot be extracted 
or calculated from BIM and instead have to be manually entered. It can be concluded that the difficulty of enriching BIM and the information richness of BIM are different at various building stages. And the in-depth synergy between MCDM and BIM is more likely to be achieved by using corresponding MCDM techniques and data collection methods for different building stages, which requires researchers to state carefully why the choice of method is suitable for the target problem. In addition, to enrich the application of MCDM in operation phase, further spectrum should be explored. For example, emergency situations is a trendy topic in facility management, such as safety evacuation simulations [83,108], rescue routing [20], critical asset location planning (e.g. fire hose [93], automated external defibrillator [55]). To enrich data in operation phase, Rojas, et al. [82] proposed alternative methods for capturing AsBuilt data for existing facilities. Son, et al. [91] also studied how to access to reliable 3D asbuilt data. In future research, MCDM can be extended to these application scenarios in operation stage by using enriched data so as to make up for the lack of research.

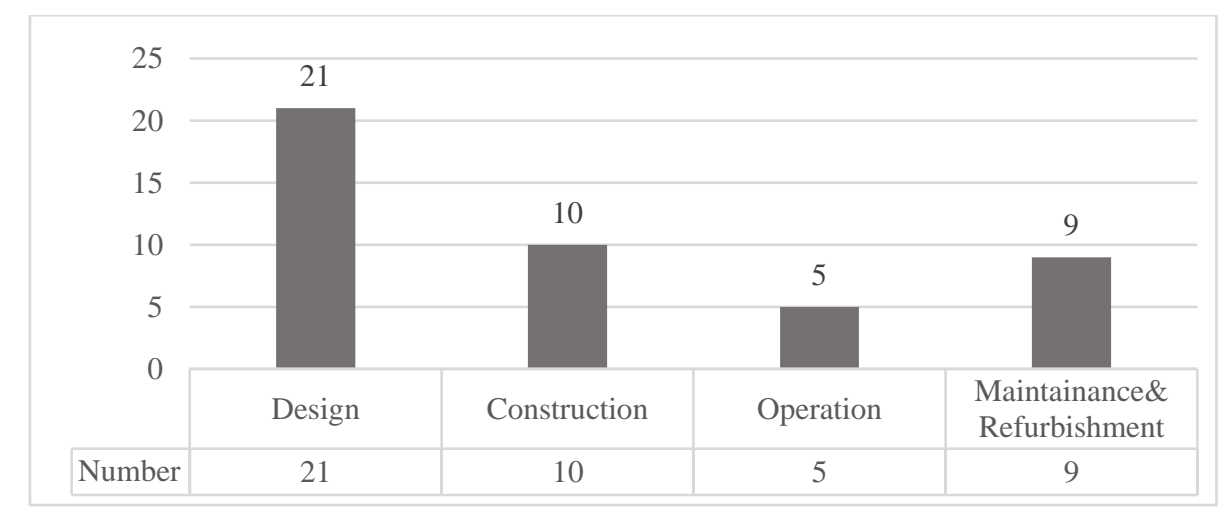

Figure 7 Categorization of reviewed papers by project lifecycle phases

\subsection{Optimize the information richness of BIM to adapt to MCDM techniques}

Different application scenarios in different building stages lead to various demand for information and data. For example, Marzouk and Abdelakder [63] defines time in their MCDM by number of crews, productivity of each crew, and nature of crews. Others may have different definition. MCDM should identify the data sources for indicators accurately based on their application scenarios. In addition, data types also matter. Crisp data and fuzzy data are two common types can be collected. The former one in MCDM depends on the experts' domain knowledge for the initial input, and differences in the source of that domain-knowledge might affect the final decision-making results. The latter in MCDM introduces fuzzy or grey theory to deal with subjectivity of human judgment and the insufficiency of information. With the development of artificial intelligence, data mining approaches are being introduced to collect objective information from real data to solve advanced decision-making problems such as 
exporting behaviour or data-rules, identifying critical factors, and forecasting performance $[59,60]$. No matter collection from experts, survey or data mining from documents, the research should provide robust evidence to defend their choice of specific methods.

Improvement strategies of BIM are needed in either low level or over level of information richness of BIM to facilitate MCDM. Our research identified two ways to achieve synergy between BIM and MCDM in a non-rich information situation. One is bridging BIM and building to enrich the information of BIM models [22], and the other is using advanced computing techniques under incomplete information environment [12]. For example, other data sources, such as GIS, various sensors, or qualitative data provided by project members, can be used as a supplement to enrich BIM. Some researchers have introduced 4D BIM [41] and 5D BIM [18] to incorporate additional dimensions of information. Some advanced computing techniques, such as Bayesian networks, can also be used to make up for the problem of imperfect BIM information [12]. The different degrees of BIM application maturity affect the semantic enrichment of BIM and thus the MCDM. In our review, some studies focus on "little BIM', namely utilizing digital models as information management hubs or repositories [30,33,80,100], and its modelling ability [15]. The successful implementation of MCDM requires integrated information from multidiscipline experts, which goes beyond 'little BIM' to 'BIG BIM' involving interrelated functional, informational, technical and organizational/legal issues [95]. Therefore, MCDM and BIM can continuously strengthen each other's attributes and roles in the process of deep interaction, thus forming a positive synergy for decision-making. More precisely, high level richness of BIM provides a data foundation for MCDM, and appropriate MCDM techniques provides a way to interpret BIM data.

\section{Conclusion and future research}

\subsection{Conclusion}

This paper reviewed 45 papers to examine previous studies about combining MCDM with BIM in the AEC industry. Selected publications involve the earliest literature (2009) of the searching result to the present (April 2020), distributing around a decade with dramatically increasing in recent two years. Five major application domains of combining MCDM with BIM were identified: sustainability, retrofit, supplier selection, safety and constructability. The review further found that the most widely used MCDM methods are AHP and TOPSIS. The major contributions of this research can be summarized threefold: (1) this article drew out and categorized the application domains and its common MCDM techniques combined with BIM; (2) this article identified three common BIM functions in synergy with MCDM, and two 
synergy approaches between BIM and MCDM; (3) this article identified five strategies used for the improvement of combining MCDM with BIM.

In reviewed papers, it can be observed that researchers may have different interpretations and definitions of emerging concepts (e.g. sustainability, DfMA, constructability). This research identifies that the concepts of goals established by a set of indicators can combine MCDM and BIM for decision-making. Besides, the integration of MCDM and BIM is theoretically postulated as a robust approach for decision-making in various application domains. MCDM and BIM can continuously strengthen each other's attributes and roles in the process of deep interaction, thus forming a positive synergy for decision-making. This kind of in-depth interaction depends on the five strategies established by the article: (1) to define the goal of decision-making by a set of rationale indicators (multi-criteria); (2) to fully exert the function of BIM; (3) to specifically design the synergy approaches between BIM and MCDM for target problems; (4) to adopt corresponding MCDM techniques and data collection methods to adapt to the characteristics of different building stages; (5) to optimize the information richness of BIM to satisfy the requirements of applied MCDM techniques.

Researchers combine MCDM techniques with BIM for its potential capabilities on model database, processing tool and information intermediary, as the rationality of decision-making is directly related to the quality of information collection and management. Improvement strategies for dealing with unsatisfied information richness of BIM includes bridging BIM and building to enrich the information of BIM models [22], and using advanced computing techniques under incomplete information environment [12]. Future research focusing on the application using MCDM and BIM can improve the reliability of the method based on the above aspects and approaches.

\subsection{Limitations and future research}

Limitations may result from the following three points. The first is the ambiguity of terms, that is, the keywords we searched may not cover all the terms used in other fields or sectors. Secondly, some articles may not involve our relevant search keywords in their titles, abstracts and keywords, but do use MCDM and BIM in the content. The third is that our search is limited to English articles. Despite the fact that the relevant literature has begun to emerge and grow in the last 10 years, it is undeniable that further research is needed (45 related studies distributed in 5 major domains) as the development of MCDM and BIM is still in its infancy stage. The following are needed to address the current research gap and expand insights:

(1) Establishing multi-criteria from subjective and objective empirical sources is the first step in applying MCDM. Both qualitative / intuitive data [43] (such as interviews, questionnaires, or brainstorming) and quantitative data (e.g. data mining) should be used. 
(2) Expand BIM in the synergy between BIM and MCDM. BIM typically functions by way of a database, or modelling tool, but the when applied with MCDM, data from BIM is often inputted, which does not fully utilize the capabilities of BIM. Future studies need to integrate MCDM and BIM in a common data environment.

(3) Synergy will be created through the in-depth interaction and integration of structures that is not simply linear. Future research on the mechanism and approaches to create interoperability and form synergy in decision-making are needed.

(4) Most studies of MCDM and BIM focus on the design stage. However, there is a need for broader application across the construction, operation, maintenance and refurbishment stages. The synergy between MCDM and BIM is expected to assist buildings in these midto-late stages to achieve rationalization and intelligent decision-making. However, there are difficulties in obtaining the latest / real-time data. Future research is needed to integrate MCDM with real-time BIM in the mid-to-late building stages.

(5) How to deal with data overload and breadth, through incremental data integration with BIM and other information sources. Integration of other data sources such as GIS, IoT, etc. need to be considered to achieve reliable MCDM. Corresponding strategies are needed.

In conclusion, these two approaches share similar integration vision and should be applied together in the AEC industry. There is a significant upward trend in the combination of MCDM with BIM in the last decade, which creates significant opportunities in advanced decisionmaking and the transformation of the AEC industry into digitization.

\section{References}

[1] T. Ahmad, M.J. Thaheem, Economic sustainability assessment of residential buildings: A dedicated assessment framework and implications for BIM, Sustainable Cities and Society 38 (2018), pp. 476-491.

[2] I. Al-Bukhari, T. Hegazy, BIM-based decision support for the evaluation of architectural submittals during construction, in: C.J. Katsanis, C. Bedard (Eds.), Proceedings, Annual Conference - Canadian Society for Civil Engineering, Vol. 1, Canadian Society for Civil Engineering, 2013, pp. 407-415.

[3] I. Albukhari, T. Hegazy, Multiple-Criteria BIM-based evaluation of architectural submittals, International Journal of Mathematical Models and Methods in Applied Sciences 9 (2015), pp. 453-462.

[4] A.F.F. Alireza, T.H. Rashidi, A. Akbarnezhad, S.T. Waller, BIM-enabled sustainability assessment of material supply decisions, Engineering, Construction and Architectural Management 24 (4) (2017), pp. 668-695.

[5] J. Antucheviciene, Z. Kala, M. Marzouk, E.R. Vaidogas, Solving civil engineering problems by means of fuzzy and stochastic MCDM methods: current state and future research, Mathematical Problems in Engineering 2015 (2015).

[6] M. Behzadian, S.K. Otaghsara, M. Yazdani, J. Ignatius, A state-of the-art survey of TOPSIS applications, Expert Systems with Applications 39 (17) (2012), pp. 1305113069.

[7] R.E. Bellman, L.A. Zadeh, Decision-making in a fuzzy environment, Management Science 17 (4) (1970), pp. B-141-B-164. 
[8] R. Benayoun, B. Roy, B. Sussman, ELECTRE: Une méthode pour guider le choix en présence de points de vue multiples, Note de travail 49 (1966).

[9] J.-P. Brans, P. Vincke, Note-A Preference Ranking Organisation Method: (The PROMETHEE Method for Multiple Criteria Decision-Making), Management Science 31 (6) (1985), pp. 647-656.

[10] J.W. Cao, H.K. Zheng, Study on cost decision model based on BIM and AHP, Applied Mechanics and Materials 584-586 (2014), pp. 2205-2208.

[11] A. Carbonari, A. Corneli, G. Di Giuda, L. Ridolfi, V. Villa, Bim-based decision support system for the management of large building stocks, ISARC. Proceedings of the International Symposium on Automation and Robotics in Construction, Vol. 35, IAARC Publications, 2018, pp. 1-8.

[12] A. Carbonari, A. Corneli, G.M. Di Giuda, L. Ridolfi, V. Villa, A decision support system for multi-criteria assessment of large building stocks, Journal of Civil Engineering and Management 25 (5) (2019), pp. 477-494.

[13] E.E. Castillo Osorio, H.H. Yoo, Simulation of evacuation route scenarios through multicriteria analysis for rescue activities, Journal of the Korean Society of Surveying, Geodesy, Photogrammetry and Cartography 37 (5) (2019), pp. 303-313.

[14] F.R. Cecconi, L.C. Tagliabue, S. Maltese, M. Zuccaro, A Multi-criteria Framework for Decision Process in Retrofit Optioneering through Interactive Data Flow, in: P. Osmond, L. Ding, F. Fiorito (Eds.), Procedia Engineering, Vol. 180, Elsevier Ltd, 2017, pp. 859-869.

[15] T. Cerovsek, A review and outlook for a 'Building Information Model'(BIM): A multistandpoint framework for technological development, Advanced Engineering Informatics 25 (2) (2011), pp. 224-244.

[16] L.-K. Chan, H. Kao, M. Wu, Rating the importance of customer needs in quality function deployment by fuzzy and entropy methods, International Journal of Production Research 37 (11) (1999), pp. 2499-2518.

[17] Y.-F. Chang, S.-G. Shih, BIM-based computer-aided architectural design, ComputerAided Design and Applications 10 (1) (2013), pp. 97-109.

[18] A. Charehzehi, C. Chai, A. Md Yusof, H.Y. Chong, S.C. Loo, Building information modeling in construction conflict management, International Journal of Engineering Business Management 9 (2017), pp. 1-18.

[19] A. Charnes, W.W. Cooper, E. Rhodes, Measuring the efficiency of decision making units, European Journal of Operational Research 2 (6) (1978), pp. 429-444.

[20] A.Y. Chen, J.C. Chu, TDVRP and BIM integrated approach for in-building emergency rescue routing, Journal of Computing in Civil Engineering 30 (5) (2016), Article C4015003.

[21] K. Chen, H. Li, AHP based weighting system for BIM implementation \& assessment framework, 2015 IEEE International Conference on Industrial Engineering and Engineering Management (IEEM), IEEE, 2015, pp. 1727-1731.

[22] K. Chen, W. Lu, Y. Peng, S. Rowlinson, G.Q. Huang, Bridging BIM and building: From a literature review to an integrated conceptual framework, International Journal of Project Management 33 (6) (2015), pp. 1405-1416.

[23] L. Chen, W. Pan, BIM-aided variable fuzzy multi-criteria decision making of lowcarbon building measures selection, Sustainable Cities and Society 27 (2016), pp. 222232.

[24] L. Chen, W. Pan, A BIM-integrated Fuzzy Multi-criteria Decision Making Model for Selecting Low-Carbon Building Measures, in: W.O. Chong, U. Berardi, K. Parrish, J. Chang (Eds.), Procedia Engineering, Vol. 118, Elsevier Ltd, 2015, pp. 606-613.

[25] Y.-H. Chen, T.-C. Wang, C.-Y. Wu, Strategic decisions using the fuzzy PROMETHEE for IS outsourcing, Expert Systems with Applications 38 (10) (2011), pp. 13216-13222.

[26] N. Dalkey, O. Helmer, An experimental application of the Delphi method to the use of experts, Management Science 9 (3) (1963), pp. 458-467. 
[27] M.M. de Brito, M. Evers, Multi-criteria decision-making for flood risk management: a survey of the current state of the art, Natural Hazards and Earth System Sciences 16 (4) (2016), pp. 1019-1033.

[28] L. Diaz-Balteiro, J. González-Pachón, C. Romero, Measuring systems sustainability with multi-criteria methods: A critical review, European Journal of Operational Research 258 (2) (2017), pp. 607-616.

[29] Z. Ding, J. Niu, S. Liu, H. Wu, J. Zuo, An approach integrating geographic information system and building information modelling to assess the building health of commercial buildings, Journal of Cleaner Production 257 (2020), Article 120532.

[30] D. Donath, Bauaufnahme und Planung im Bestand, Springer, 2009.

[31] L. Dong, J. Wu, W. Wang, Y. Zhou, Visualization of Foundation Evaluation for Urban Rail Transit Based on CGB Technology Integration Visualization of Foundation Evaluation for Urban Rail Transit Based on CGB Technology Integration, International Journal of Sustainable Development and Planning 15 (4) (2020), pp. 477-486.

[32] P.H. Dos Santos, S.M. Neves, D.O. Sant'Anna, C.H. de Oliveira, H.D. Carvalho, The analytic hierarchy process supporting decision making for sustainable development: An overview of applications, Journal of Cleaner Production 212 (2019), pp. 119-138.

[33] C.M. Eastman, C. Eastman, P. Teicholz, R. Sacks, K. Liston, BIM handbook: A guide to building information modeling for owners, managers, designers, engineers and contractors, John Wiley \& Sons, 2011.

[34] W. Edwards, How to use multiattribute utility measurement for social decisionmaking, IEEE Transactions on Systems, Man, \& Cybernetics 7 (5) (1977), pp. 326-340.

[35] S. Elonen, K.A. Artto, Problems in managing internal development projects in multiproject environments, International Journal of Project Management 21 (6) (2003), pp. 395-402.

[36] A. Fazeli, F. Jalaei, M. Khanzadi, S. Banihashemi, BIM-integrated TOPSIS-Fuzzy framework to optimize selection of sustainable building components, International Journal of Construction Management (2019), pp. 1-20.

[37] F. Fouchal, T.M. Hassan, S.K. Firth, Maintenance, retrofit and operation decision support tool for both domestic and non-domestic buildings, in: R.R. Issa, I. Flood (Eds.), Proceedings of the 2014 International Conference on Computing in Civil and Building Engineering, American Society of Civil Engineers (ASCE), 2014, pp. 1699-1706.

[38] S. Gao, R. Jin, W.J.B.R. Lu, Information, Design for manufacture and assembly in construction: a review, Building Research \& Information (2019), pp. 1-13.

[39] A.Q. Gbadamosi, A.M. Mahamadu, L.O. Oyedele, O.O. Akinade, P. Manu, L. Mahdjoubi, C. Aigbavboa, Offsite construction: Developing a BIM-Based optimizer for assembly, Journal of Cleaner Production 215 (2019), pp. 1180-1190.

[40] A. Grilo, A. Zutshi, R. Jardim-Goncalves, A. Steiger-Garcao, Construction collaborative networks: the case study of a building information modelling-based office building project, International Journal of Computer Integrated Manufacturing 26 (1-2) (2013), pp. 152-165.

[41] W. Hijazi, S. Alkass P, Tarek, Zayed, Constructability assessment using BIM/4D CAD simulation model, AACE International Transactions, Vol. 4, Association for the Advancement of Cost Engineering, 2009, pp. 1-14.

[42] W. Hijazi, S. Alkass, T. Zayed, Constructability assessment framework using BIM technology, Proceedings, Annual Conference - Canadian Society for Civil Engineering, Vol. 3, 2009, pp. 1334-1343.

[43] A. Ishizaka, S. Siraj, Are multi-criteria decision-making tools useful? An experimental comparative study of three methods, European Journal of Operational Research 264 (2) (2018), pp. 462-471.

[44] F. Jalaei, A. Jrade, M. Nassiri, Integrating decision support system (DSS) and building information modeling (BIM) to optimize the selection of sustainable building components, Journal of Information Technology in Construction 20 (2015), pp. 399420 . 
[45] E. Jalilzadehazhari, P. Johansson, Integrating BIM, Optimization and a Multi-criteria Decision-Making Method in Building Design Process, Advances in Informatics and Computing in Civil and Construction Engineering, Springer, 2019, pp. 359-369.

[46] E. Jalilzadehazhari, A. Vadiee, P. Johansson, Achieving a trade-off construction solution using BIM, an optimization algorithm, and a multi-criteria decision-making method, Buildings 9 (4) (2019), pp. 1-14, Article 81.

[47] L. Janeiro, M.K. Patel, Choosing sustainable technologies. Implications of the underlying sustainability paradigm in the decision-making process, Journal of Cleaner Production 105 (2015), pp. 438-446.

[48] D. Jato-Espino, E. Castillo-Lopez, J. Rodriguez-Hernandez, J.C. Canteras-Jordana, A review of application of multi-criteria decision making methods in construction, Automation in Construction 45 (2014), pp. 151-162.

[49] E. Jazayeri, G.B. Dadi, Construction safety management systems and methods of safety performance measurement: A review, Journal of Safety Engineering 6 (2) (2017), pp. $15-28$.

[50] M. Juszczyk, K. Zima, Analysis of the possibility of selecting green facades in the decision making process, International Multidisciplinary Scientific GeoConference Surveying Geology and Mining Ecology Management, SGEM, Vol. 18, International Multidisciplinary Scientific Geoconference, 2018, pp. 59-66.

[51] G. Kabir, R. Sadiq, S. Tesfamariam, A review of multi-criteria decision-making methods for infrastructure management, Structure and Infrastructure Engineering 10 (9) (2014), pp. 1176-1210.

[52] J. Kangas, A. Kangas, P. Leskinen, J. Pykäläinen, MCDM methods in strategic planning of forestry on state-owned lands in Finland: applications and experiences, Journal of Multi-Criteria Decision Analysis 10 (5) (2001), pp. 257-271.

[53] M. Khanzadi, A. Kaveh, M.R. Moghaddam, S.M. Pourbagheri, Optimization of building components with sustainability aspects in BIM environment, Periodica Polytechnica Civil Engineering 63 (1) (2019), pp. 93-103.

[54] J.I. Kim, J. Kim, M. Fischer, R. Orr, BIM-based decision-support method for master planning of sustainable large-scale developments, Automation in Construction 58 (2015), pp. 95-108.

[55] C.-T. Lee, Y.-C. Lee, A.Y. Chen, In-building automated external defibrillator location planning and assessment through building information models, Automation in Construction 106 (2019), Article 102883.

[56] P.C. Lee, T.P. Lo, M.Y. Tian, D. Long, An Efficient Design Support System based on Automatic Rule Checking and Case-based Reasoning, KSCE Journal of Civil Engineering (2019).

[57] C.-C. Lin, W.-C. Wang, W.-D. Yu, Improving AHP for construction with an adaptive AHP approach (A3), Automation in Construction 17 (2) (2008), pp. 180-187.

[58] I. Linkov, A. Varghese, S. Jamil, T.P. Seager, G. Kiker, T. Bridges, Multi-criteria decision analysis: a framework for structuring remedial decisions at contaminated sites, Comparative Risk Assessment and Environmental Decision Making, Springer, 2004, pp. 15-54.

[59] J.J. Liou, Y.-C. Chuang, E.K. Zavadskas, G.-H. Tzeng, Data-driven hybrid multiple attribute decision-making model for green supplier evaluation and performance improvement, Journal of Cleaner Production 241 (2019), pp. 1-12.

[60] L. Luo, X. Liang, C. Fang, Z. Wu, X. Wang, Y. Wang, How to promote prefabricated building projects through internet of things? A game theory-based analysis, Journal of Cleaner Production 276 (2020), p. 124325.

[61] A.-M. Mahamadu, L. Mahdjoubi, C. Booth, Supplier BIM competence assessments within the cloud: a proposed Fuzzy-TOPSIS approach, BIM (2015), pp. 71-82.

[62] S. Mahmoud, T. Zayed, M. Fahmy, Development of sustainability assessment tool for existing buildings, Sustainable Cities and Society 44 (2019), pp. 99-119.

[63] M. Marzouk, M. Abdelakder, A hybrid fuzzy-optimization method for modeling construction emissions, Decision Science Letters 9 (1) (2020), pp. 1-20. 
[64] M. Marzouk, E.M. Abdelkader, Minimizing Construction Emissions Using Building Information Modeling and Decision-Making Techniques, International Journal of 3-D Information Modeling 6 (2) (2017), pp. 14-35.

[65] M. Marzouk, I.A. Daour, Planning labor evacuation for construction sites using BIM and agent-based simulation, Safety Science 109 (2018), pp. 174-185.

[66] J. Melzner, S. Hollermann, H.J. Bargstädt, A multi-criteria decision-support approach for fall protection planning, Proceedings of the European Conference on Product and Process Modelling 2012, ECPPM 2012, 2012, pp. 675-680.

[67] D. Migilinskas, M. Pavlovskis, I. Urba, V. Zigmund, Analysis of problems, consequences and solutions for BIM application in reconstruction projects, Journal of Civil Engineering and Management 23 (8) (2017), pp. 1082-1090.

[68] J.E. Moore, A. Mascarenhas, J. Bain, S.E. Straus, Developing a comprehensive definition of sustainability, Implementation Science 12 (1) (2017), p. 110.

[69] S. Nădăban, S. Dzitac, I. Dzitac, Fuzzy topsis: A general view, Procedia Computer Science 91 (2016), pp. 823-831.

[70] H.I. Naji, M. Mahmood, H.E. Mohammad, Using BIM to propose building alternatives towards lower consumption of electric power in Iraq, Asian Journal of Civil Engineering 20 (5) (2019), pp. 669-679.

[71] M.N.M. Nawi, A. Lee, M.N.A. Azman, K.A.M. Kamar, Fragmentation issue in Malaysian industrialised building system (IBS) projects, Journal of Engineering Science and Technology 9 (1) (2014), pp. 97-106.

[72] S. Opricovic, Programski paket VIKOR za visekriterijumsko kompromisno rangiranje, 17th International Symposium on Operational Research SYM-OP-IS, 1990.

[73] S.K. Patil, R. Kant, A fuzzy AHP-TOPSIS framework for ranking the solutions of Knowledge Management adoption in Supply Chain to overcome its barriers, Expert Systems with Applications 41 (2) (2014), pp. 679-693.

[74] M. Pavlovskis, J. Antucheviciene, D. Migilinskas, Application of MCDM and BIM for evaluation of asset redevelopment solutions, Studies in Informatics and Control 25 (3) (2016), pp. 293-302.

[75] M. Pavlovskis, J. Antucheviciene, D. Migilinskas, Assessment of Buildings Redevelopment Possibilities using MCDM and BIM Techniques, in: A. Daniunas, E.K. Zavadskas, A. Juozapaitis (Eds.), Procedia Engineering, Vol. 172, Elsevier Ltd, 2017, pp. 846-850.

[76] M. Pavlovskis, D. Migilinskas, J. Antucheviciene, V. Kutut, Ranking of heritage building conversion alternatives by applying BIM and MCDM: A case of Sapieha Palace in Vilnius, Symmetry 11 (8) (2019), Article 973.

[77] M. Petticrew, Systematic reviews from astronomy to zoology: myths and misconceptions, BMJ 322 (7278) (2001), pp. 98-101.

[78] J.B. Pocock, S.T. Kuennen, J. Gambatese, J. Rauschkolb, Constructability state of practice report, Journal of Construction Engineering and Management 132 (4) (2006), pp. 373-383.

[79] Y. Ranjbaran, O. Moselhi, 4D-based value engineering, Construction Research Congress 2014, American Society of Civil Engineers (ASCE), 2014, pp. 1606-1615.

[80] A. Redmond, A. Hore, M. Alshawi, R. West, Exploring how information exchanges can be enhanced through Cloud BIM, Automation in Construction 24 (2012), pp. 175183.

[81] K. Renganath, M. Suresh, Supplier selection using fuzzy MCDM techniques: A literature review, 2016 IEEE International Conference on Computational Intelligence and Computing Research (ICCIC), IEEE, 2016, pp. 1-6.

[82] E.M. Rojas, C.S. Dossick, J. Schaufelberger, B.A. Brucker, H. Juan, C. Rutz, Evaluating alternative methods for capturing as-built data for existing facilities, International Workshop on Computing in Civil Engineering 2009, 2009, pp. 237-246.

[83] U. Rüppel, K. Schatz, Designing a BIM-based serious game for fire safety evacuation simulations, Advanced Engineering Informatics 25 (4) (2011), pp. 600-611. 
[84] T.L. Saaty, Decision making with dependence and feedback: The analytic network process, RWS Publ., 1996.

[85] T.L. Saaty, Decision making with the analytic hierarchy process, International Journal of Services Sciences 1 (1) (2008), pp. 83-98.

[86] T.L. Saaty, Fundamentals of the analytic network process, Proceedings of the 5th International Symposium on the Analytic Hierarchy Process, 1999, pp. 12-14.

[87] T.L. Saaty, What is the analytic hierarchy process?, Mathematical Models for Decision Support, Springer, 1988, pp. 109-121.

[88] T.L. Saaty, L.G. Vargas, The analytic network process, Decision making with the analytic network process, Springer, 2013, pp. 1-40.

[89] L.A. Sierra, V. Yepes, E. Pellicer, A review of multi-criteria assessment of the social sustainability of infrastructures, Journal of Cleaner Production 187 (2018), pp. 496513.

[90] V. Singh, N. Gu, X. Wang, A theoretical framework of a BIM-based multi-disciplinary collaboration platform, Automation in Construction 20 (2) (2011), pp. 134-144.

[91] H. Son, F. Bosché, C. Kim, As-built data acquisition and its use in production monitoring and automated layout of civil infrastructure: A survey, Advanced Engineering Informatics 29 (2) (2015), pp. 172-183.

[92] S. Staub-French, M. Fischer, J. Kunz, B. Paulson, A generic feature-driven activitybased cost estimation process, Advanced Engineering Informatics 17 (1) (2003), pp. 23-39.

[93] T.-A. Teo, K.-H. Cho, BIM-oriented indoor network model for indoor and outdoor combined route planning, Advanced Engineering Informatics 30 (3) (2016), pp. 268282.

[94] E. Triantaphyllou, Multi-criteria decision making methods, Multi-criteria decision making methods: A comparative study, Springer, 2000, pp. 5-21.

[95] R. Volk, J. Stengel, F. Schultmann, Building Information Modeling (BIM) for existing buildings - Literature review and future needs, Automation in Construction 38 (2014), pp. 109-127.

[96] J. Wallenius, J.S. Dyer, P.C. Fishburn, R.E. Steuer, S. Zionts, K. Deb, Multiple criteria decision making, multiattribute utility theory: Recent accomplishments and what lies ahead, Management Science 54 (7) (2008), pp. 1336-1349.

[97] H. Wang, Application research of BIM in environment assessment of full life cycle for construction projects, Proceedings - 2017 International Conference on Smart Grid and Electrical Automation, ICSGEA 2017, Institute of Electrical and Electronics Engineers Inc., 2017, pp. 652-655.

[98] T.K. Wang, Y. Piao, Development of BIM-AR-Based Facility Risk Assessment and Maintenance System, Journal of Performance of Constructed Facilities 33 (6) (2019), Article 04019068.

[99] T.K. Wang, Q. Zhang, H.Y. Chong, X. Wang, Integrated supplier selection framework in a resilient construction supply chain: An approach via analytic hierarchy process (AHP) and grey relational analysis (GRA), Sustainability (Switzerland) 9 (2) (2017), Article 289.

[100] A. Watson, Digital buildings-Challenges and opportunities, Advanced Engineering Informatics 25 (4) (2011), pp. 573-581.

[101] J.H. Woo, C. Menassa, Virtual Retrofit Model for aging commercial buildings in a smart grid environment, Energy and Buildings 80 (2014), pp. 424-435.

[102] W. Xu, T.-K. Wang, Dynamic safety prewarning mechanism of human-machineenvironment using computer vision, Engineering, Construction and Architectural Management (2020).

[103] K. Yoon, C.L. Hwang, TOPSIS (technique for order preference by similarity to ideal solution)-a multiple attribute decision making, w: Multiple attribute decision makingmethods and applications, a state-of-the-at survey, Berlin: Springer Verlag (1981). 
[104] Y. Yu, S.J. Woo, A study on the model of a building-envelope structural modification system to increase energy efficiency at the schematic design stage, Journal of Asian Architecture and Building Engineering 12 (2) (2013), pp. 189-196.

[105] E.K. Zavadskas, Z. Turskis, J. Antucheviciene, A. Zakarevicius, Optimization of weighted aggregated sum product assessment, Elektronika ir Elektrotechnika 122 (6) (2012), pp. 3-6.

[106] H. Zhang, Design and Implementation of BIM-based Fire Risk Assessment System, Journal of Physics: Conference Series, Vol. 1584, IOP Publishing, 2020.

[107] L. Zhao, Z. Liu, J. Mbachu, Optimization of the supplier selection process in prefabrication using BIM, Buildings 9 (10) (2019), Article 222.

[108] H. Zou, N. Li, L. Cao, Emotional response-based approach for assessing the sense of presence of subjects in virtual building evacuation studies, Journal of Computing in Civil Engineering 31 (5) (2017), Article 04017028. 